\title{
EFFECTS IN $V I V O$ OF NEUROHYPOPHYSIAL HORMONES ON THE CONTRACTILE ACTIVITY OF ACCESSORY SEX ORGANS IN MALE RABBITS
}

\author{
PER MELIN \\ Institute of Zoophysiology, University of Uppsala, Sweden \\ (Received 23rd Fune 1969, revised 22nd September 1969)
}

Summary. The effects of single intravenous injections of synthetic oxytocin and lysine-vasopressin on the contractile activity of the distal part of the ductus epididymidis, the proximal and distal parts of the vas deferens and the vesicula seminalis were studied in seventy-two anaesthetized rabbits. The muscular contractions were registered as changes in the intraluminal pressure of the organs, and the amplitude, frequency, duration and tonus were measured.

An injection of $20 \mathrm{~m}$-i.u. of oxytocin $/ \mathrm{kg}$ body weight caused a small but significant increase of the amplitude of the contractions in the ductus epididymidis and the proximal part of the vas deferens. An injection of $100 \mathrm{~m}-i . u$. of oxytocin increased the tone in the proximal part of the vas deferens but decreased this parameter in the distal part of the organ. The infusion of $20 \mathrm{~m}$-i.u. of vasopressin enhanced the frequency, decreased the duration and elevated the muscular tone in the ductus epididymidis and increased the frequency and the tone in the proximal part of the vas deferens. The infusion of $100 \mathrm{~m}$-i.u. of vasopressin resulted in increased amplitudes in both these regions. A gradual increase in the effects of oxytocin and vasopressin towards the testis was observed, indicating a polarity in response to the hormones of the male reproductive ducts.

The results support the theory that neurohypophysial hormones may regulate sperm transport in the male through their effects on the contractile elements of the genital organs, possibly being complementary in their actions.

\section{INTRODUCTION}

In recent years, oxytocin has been observed to have immediate effects on male sexual functions, such as libido, transport of spermatozoa and the discharge of semen (Bereznev, 1963; Ewy \& Bielansky, 1962; Kihlström \& Melin, 1963; Melin \& Kihlström, 1963; Levin, 1966; Fjellström, Kihlström \& Melin, 1968).

It seems reasonable to attribute the reported effects of oxytocin to a stimulating action of the hormone on the contractile elements of the male genital organs, though the majority of investigations on the subject do not give much 
evidence for such an effect either in vitro (Waddell, 1916, 1917; Perutz \& Merdler, 1924; Martins \& Valle, 1939; Wojcik, 1966; Sjöstrand \& Swedin, 1968) or in vivo (Cross \& Glover, 1958; Cross, 1959).

This study was undertaken in view of the previous conflicting reports and the apparent lack of systematic observations of the effects of oxytocin on the male genital organs. Since the secretion of oxytocin from the neurohypophysis is, as a rule, accompanied by a simultaneous release of vasopressin (Heller, 1961), this hormone was included in the investigation.

The present work deals with the influence of oxytocin and vasopressin on the contractile activity of the distal part of the ductus epididymidis, the vas deferens and the vesicula seminalis, using a quantitative method, an adequate recording system and statistical treatment.

\section{MATERIAL AND METHODS}

Seventy-two male rabbits about 1 year old, weighing 2.6 to $3.4 \mathrm{~kg}$ and of mixed breeds were used. The animals had been caged separately and been given the same kind of food at regular times, for at least a fortnight before the experiments.

The rabbits were anaesthetized by intravenous injections of Numal (Roche) $(0.5 \mathrm{ml} / \mathrm{kg}$ body weight $)$. Supplementary doses of the anaesthetic were administered throughout the experiments, to keep the depth of anaesthesia as constant as possible. Tracheotomy was generally performed to facilitate respiration and an external jugular vein was cannulated to assist the giving of injections during the experiments. The remaining surgical procedures and the intraluminal pressure measurements in the different parts of the male genital tract were performed according to the methods described by Melin (1970).

The organs were allowed to adapt themselves to the new conditions for about 30 min before the experimental injections started. Only one kind of preparation was studied in each animal and for each preparation the following main criteria were to be fulfilled before the start of the injections: there was to be no excessive bleeding caused by the surgical manipulations, the drift of muscular tone was not to exceed $0.2 \mathrm{~mm} \mathrm{H}_{2} \mathrm{O} / \mathrm{min}$ and the different regions of the tract were to respond to intravenous injections of adrenalin ( 2 to $4 \mu \mathrm{g} / \mathrm{kg}$ body weight) with a single momentary contraction (latency 8 to $15 \mathrm{sec}$ ) (Plate 1). As a rule, there was a slow decrease with time in the muscular activities of the different preparations of the genital tract (probably mainly due to absorption of the intraluminal fluid by tissue elements and consequent decrease of the initial pressure). To reduce this drawback, both sides of the animals were used for the pressure measurements.

The hormones used were synthetic oxytocin (Partocon, Ferring $\mathrm{AB}$ ) and lysine-vasopressin (Postacton, Ferring AB) in initial concentrations of $10 \mathrm{i} . \mathrm{u} . / \mathrm{ml}$. Two different doses of the hormones were tested, $20 \mathrm{~m}$-i.u. and $100 \mathrm{~m}$-i.u. $/ \mathrm{kg}$ body weight. After the requisite dilution with saline, the hormones were each given as a single intravenous injection in a volume of $0.5 \mathrm{ml}$. Immediately after each infusion, the injection cannula was rinsed with an injection of the same amount of saline.

Differences in the contractile patterns were observed for two consecutive 
PLATE 1
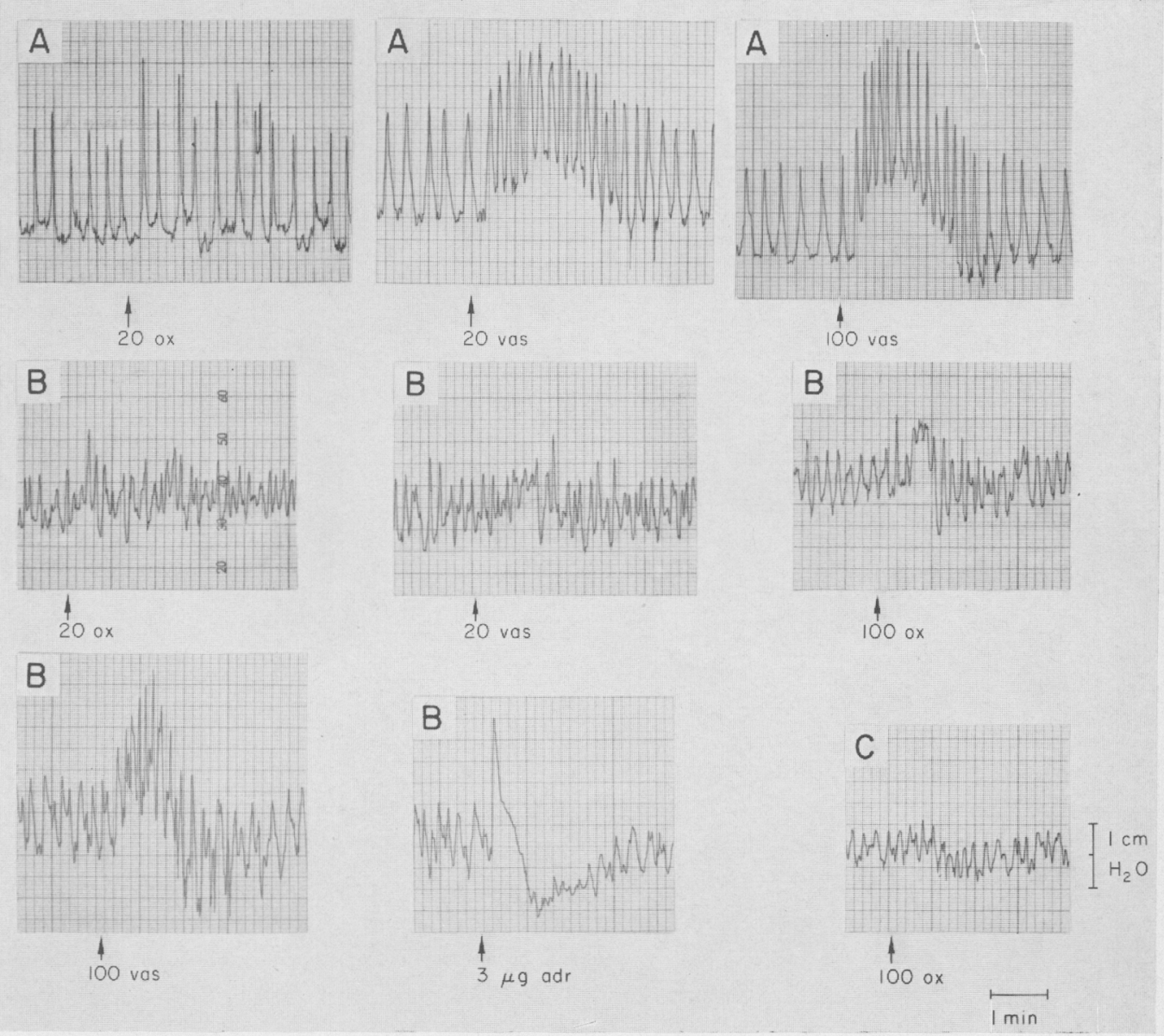

Influence of oxytocin (ox) and vasopressin (vas) on the intraluminal pressure of the ductus epididymidis $(A)$, the vas deferens, proximal part $(B)$ and the vas deferens, distal part $(\mathrm{C})$. Note biphasic responses, showing similarities to the effect of adrenalin (adr). Doses lacking significant effects excluded. Doses in m-i.u. 
periods of $3 \mathrm{~min}$, one period starting with a saline injection and the other with a hormone injection. At least $15 \mathrm{~min}$ were allowed to intervene between each new injection of the hormone. To avoid statistical bias due to tachyphylaxis, the order of infusion of the hormones was altered for each preparation.

The following characteristics of contractile activity were noted:

The amplitude of the contractions, measured as the registered height of each contraction (variations in pressure of $1 \mathrm{~mm} \mathrm{H}_{2} \mathrm{O}$ or less were neglected).

The frequency, counted as the number of contractions per min.

The duration, giving the time in seconds from the start of each contraction to the end of the relaxation phase.

The tonus change, determined as a change in the level of the base line (a line drawn through the mean value of the minimum level of each contraction).

The data obtained were calculated as mean values from at least two pairs of observation periods, per dose and per animal, each period of the pair starting with an injection of saline and of a hormone, respectively. A value of $P=0.05$ less was considered significant.

\section{RESULTS}

The general effects of the hormones on muscle contractility are shown in Table 1 , which gives the significances of the pooled data. As a rule, the effects persisted for only a few minutes (latency 10 to $15 \mathrm{sec}$ ) after injection of the hormones. Representative records of the significant responses are shown in Plate 1.

\section{Ductus epididymidis}

$20 m$-i.u. of oxytocin. This dose caused a moderate but highly significant enhancement of the amplitude of muscular contractions $(P<0 \cdot 001$, Table 1 , Plate 1). The mean frequency and the mean duration were not influenced by injections of $20 \mathrm{~m}$-i.u. of oxytocin, nor was the tone significantly altered.

In a few cases (Table 2), there was a slight but significant biphasic response to the hormone: an increase of the tone occurred and was followed by a decrease (latency 45 to $80 \mathrm{sec}$ ).

$100 m$-i.u. of oxytocin. This higher dose of oxytocin had no significant influence on any of the parameters investigated (Table 1, Plate 1). The biphasic response appeared in two cases out of eighteen (Table 2).

The lack of effect of the larger amount of oxytocin on the amplitude is mainly due to the fact that the number of individuals showing a decrease of this parameter has increased.

$20 m$-i.u. of vasopressin. There was no significant change in the amplitude of the contractions as a result of the vasopressin injections (Table 1, Plate 1). However, this amount of vasopressin increased the number of contractions per $\min$ in fifteen out of eighteen individuals by more than $30 \%(P<0 \cdot 001)$. The duration of the contraction was shortened $(P<0.01)$ and there was an elevation of the muscular tone $(P<0.001)$. The biphasic responses were shown by $25 \%$ of the individuals (Table 2).

$100 \mathrm{~m}$-i.u. of vasopressin. This dose of the hormone caused significant enhancement of the amplitude $(P<0.01)$, as well as of the frequency $(P<0.025)$ of the 


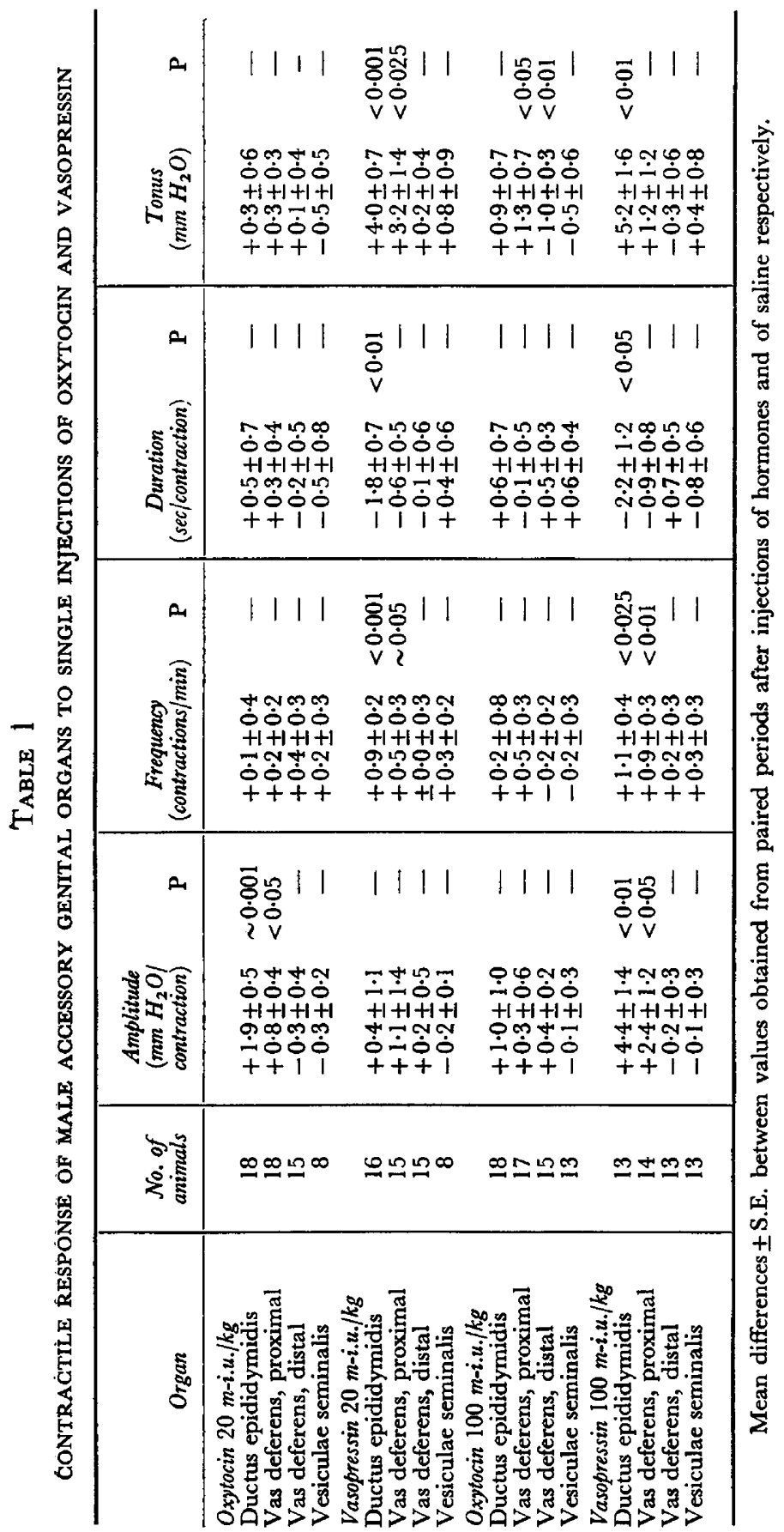


contractions (Table 1). In addition, there was a shortening of the duration $(P<0.05)$ and an increased tone $(P<0 \cdot 01)$. Twenty-three per cent of the individuals exhibited biphasic responses (Table 2).

Vas deferens, proximal part

$20 m$-i.u. of oxytocin. The oxytocin injections caused a slight but significant increase in amplitude, less obvious than in the ductus epididymidis $(P<0.05$, Table 1, Plate 1).

$100 m-i . u$. of oxytocin. As with the preparations of the ductus epididymidis, there were no significant changes of any of the parameters studied, following injections of the higher dose of oxytocin, except for a slight elevation of tone $(P<0.05)$. The biphasic responses occurred in $29 \%$ of the cases.

TABLE 2

INFLUENCE OF OXYTOCIN AND VASOPRESSIN ON CONTRACTILE BEHAVIOUR OF THE MALE GENITAL TRACT

\begin{tabular}{|c|c|c|c|}
\hline Organ & \multicolumn{2}{|c|}{$\begin{array}{c}\text { No. of animals: } \\
\text { Total } \\
\begin{array}{c}\text { With biphasic } \\
\text { response* }\end{array}\end{array}$} & $\begin{array}{l}\% \text { animals } \\
\text { with biphasic } \\
\text { response }\end{array}$ \\
\hline $\begin{array}{l}\text { Oxytocin } 20 \mathrm{~m} \text {-i.u. } / \mathrm{kg} \\
\text { Ductus epididymidis } \\
\text { Vas deferens, proximal } \\
\text { Vas deferens, distal }\end{array}$ & $\begin{array}{l}18 \\
18 \\
15\end{array}$ & $\begin{array}{l}2 \\
1 \\
4\end{array}$ & $\begin{array}{r}11 \\
7 \\
27\end{array}$ \\
\hline $\begin{array}{l}\text { Vasopressin } 20 \mathrm{~m}-\mathrm{i} . u . / \mathrm{kg} \\
\text { Ductus epididymidis } \\
\text { Vas deferens, proximal } \\
\text { Vas deferens, distal }\end{array}$ & $\begin{array}{l}16 \\
15 \\
15\end{array}$ & $\begin{array}{l}4 \\
2 \\
6\end{array}$ & $\begin{array}{l}25 \\
13 \\
40\end{array}$ \\
\hline $\begin{array}{l}\text { Oxytocin } 100 \mathrm{~m} \text {-i.u. } / \mathrm{kg} \\
\text { Ductus epididymidis } \\
\text { Vas deferens, proximal } \\
\text { Vas deferens, distal }\end{array}$ & $\begin{array}{l}18 \\
17 \\
15\end{array}$ & $\begin{array}{l}2 \\
5 \\
4\end{array}$ & $\begin{array}{l}11 \\
29 \\
27\end{array}$ \\
\hline $\begin{array}{l}\text { Vasopressin } 100 \mathrm{~m} \text {-i.u. } / \mathrm{kg} \\
\text { Ductus epididymidis } \\
\text { Vas deferens, proximal } \\
\text { Vas deferens, distal }\end{array}$ & $\begin{array}{l}13 \\
14 \\
13\end{array}$ & $\begin{array}{l}3 \\
7 \\
7\end{array}$ & $\begin{array}{l}23 \\
50 \\
54\end{array}$ \\
\hline
\end{tabular}

* Number of individuals showing significant biphasic responses $(P<0.05)$.

$20 m$-i.u. of vasopressin. The stimulating effect of the hormone on the frequency of contractions in the region of the ductus epididymidis was considerably smaller in the proximal part of the vas deferens $(P<0.05)$. The vasopressin injection induced rhythmic contractions in a single preparation lacking spontaneous motility. There was a moderate increase in tone during the observation period after the hormone administration $(P<0.025$, Plate 1$)$. The biphasic responses were rarely seen $(13 \%$, Table 2$)$.

$100 \mathrm{~m}$-i.u. of vasopressin. The effects of this amount seemed to be accentuated in comparison with the lower dose (Table 1). There was a moderate elevation of the amplitude of each contraction $(P<0.05)$, as well as an increase in the frequency of contractions $(P<0.01)$. Significant biphasic responses were shown by half the preparations (Table 2): the momentary elevation in muscular tone was followed by a marked decrease (Plate 1), which made changes in the 
average tone during the whole period after the hormone injection insignificant. In addition, there was sometimes an inhibition of the contractions following upon the decrease in tone.

Vas deferens, distal part

$20 \mathrm{~m}$-i.u. of oxytocin. No significant changes were observed (Table 1). However, in $27 \%$ of the individuals (Table 2), there was a biphasic response of the same type as described earlier.

100 m-i.u. of oxytocin. The higher dose of oxytocin used did not cause any significant change in the amplitude, frequency or duration of contractions. In $27 \%$ of the preparations, there was a significant biphasic response to the hormone (Table 2) with a low tonus predominating. However, in most individuals, only the second phase of the original biphasic response was present (Plate 1). Consequently, there was a lessening of the average tone $(P<0.01)$ during the observation period after the oxytocin injection.

$20 \mathrm{~m}$-i.u. of vasopressin. The dose did not produce significant changes in any of the different parameters of motility, though biphasic responses were rather common $(40 \%$, Table 2$)$.

$100 m$-i.u. of vasopressin. There was no alteration of any of the parameters studied, though in the majority of the preparations, the vasopressin infusions did produce a significant biphasic response (Table 2): the tonus increase during the first minute after the injection was followed by a later decrease, resulting in a total tonus change, during the period, of about zero (Table 1).

\section{Vesicula seminalis}

20 and $100 \mathrm{~m}$-i.u. of oxytocin. There were no significant changes in any characteristics of the motility pattern of this organ following injections of the hormone (Table 1), though as before, individual responses occurred.

20 and 100 m-i.u. of vasopressin. Neither of these doses of vasopressin were able to produce any changes in the motility of the organ (Table 1). However, in some cases, there was a lessening of the tone during the latter half of the period following upon the hormone injection.

Significant biphasic responses were not observed in this region.

\section{DISCUSSION}

It is known from studies of the rabbit uterus (Csapo, 1961) that the threshold dose of oxytocin is low and the effect more pronounced, when the organ possesses a high degree of excitability, manifested, as a rule, in well-developed, spontaneous, rhythmic contractions. It appears to be of interest to investigate whether this observation also holds good for the male genital organs. Thus, for example, the highly significant reaction to neurohypophysial hormones by the ductus epididymidis may be connected with the great amplitude of the contractions observed in this region (Melin, 1970). Besides, the differences in motility found between the genital tracts investigated in untreated animals (Melin, 1970) may possibly be dependent on the experimental situation. This being the case, the present observations on differences between regions in 
response to the hormones may not represent true phenomena. It has, thus, been considered relevant, in the analysis presented below, to include only those cases in which injections of the hormones have produced significant changes of the different parameters of contraction. The term 'magnitude of response', here denoted by $\Delta R$, is to be understood as the mean difference between each of the parameters of muscular contraction observed during periods immediately following an injection of a hormone and of saline, respectively. This difference has been referred to the different parameters of spontaneous motility, studied during periods preceding a hormone injection. The correlations are given in Table 3.

In the ductus epididymidis, neither $20 \mathrm{~m}$-i.u. of oxytocin nor $100 \mathrm{~m}$-i.u. of vasopressin yielded any significant correlation between $\Delta \mathrm{R}$ and the amplitude of contractions. Moreover, both doses of vasopressin failed to yield any significant

TABLE 3

MAGNITUDE OF RESPONSE $(\Delta \mathbf{R})$ TO OXYTOGIN AND VASOPRESSIN, GORRELATED WTTH DIFFERENT PARAMETERS OF GONTRACTILE AGTIVITY

\begin{tabular}{|c|c|c|c|c|c|c|c|}
\hline Region & Hormone & $\begin{array}{c}\text { Dose } \\
(m-i . u . / k g)\end{array}$ & $\begin{array}{l}\text { Independent } \\
\text { variable }\end{array}$ & $\begin{array}{l}\text { Dependent } \\
\text { variable }\end{array}$ & $\begin{array}{c}\text { No. of } \\
\text { animals }\end{array}$ & $r$ & $\mathbf{P}$ \\
\hline $\begin{array}{l}\text { Ductus } \\
\text { epididymidis }\end{array}$ & $\begin{array}{l}\text { Oxytocin } \\
\text { Vasopressin } \\
\text { Vasopressin } \\
\text { Vasopressin } \\
\text { Vasopressin } \\
\text { Vasopressin }\end{array}$ & $\begin{array}{r}20 \\
100 \\
20 \\
100 \\
20 \\
100\end{array}$ & $\begin{array}{l}\text { Amplitude } \\
\text { Amplitude } \\
\text { Frequency } \\
\text { Frequency } \\
\text { Duration } \\
\text { Duration }\end{array}$ & $\begin{array}{l}\Delta \mathrm{R}_{\mathrm{a}} \\
\Delta \mathrm{R}_{\mathrm{a}} \\
\Delta \mathrm{R}_{\mathrm{f}} \\
\Delta \mathrm{R}_{\mathrm{f}} \\
\Delta \mathrm{R}_{\mathrm{d}} \\
\Delta \mathrm{R}_{\mathrm{d}}\end{array}$ & $\begin{array}{l}18 \\
18 \\
16 \\
13 \\
16 \\
13\end{array}$ & $\begin{array}{l}+0.34 \\
+0.23 \\
-0.19 \\
-0.30 \\
-0.73 \\
-0.73\end{array}$ & $\begin{array}{l}\bar{Z} \\
\overline{-} \\
<0.01 \\
<0.01\end{array}$ \\
\hline $\begin{array}{l}\text { Vas deferens, } \\
\text { proximal } \\
\text { part }\end{array}$ & $\begin{array}{l}\text { Oxytocin } \\
\text { Vasopressin } \\
\text { Vasopressin } \\
\text { Vasopressin }\end{array}$ & $\begin{array}{r}20 \\
100 \\
20 \\
100\end{array}$ & $\begin{array}{l}\text { Amplitude } \\
\text { Amplitude } \\
\text { Frequency } \\
\text { Frequency }\end{array}$ & $\begin{array}{l}\Delta \mathrm{R}_{\mathrm{a}} \\
\Delta \mathrm{R}_{\mathrm{a}} \\
\Delta \mathrm{R}_{\mathrm{f}} \\
\Delta \mathrm{R}_{\mathrm{f}}\end{array}$ & $\begin{array}{l}18 \\
14 \\
15 \\
14\end{array}$ & $\begin{array}{l}+0.33 \\
-0.59 \\
-0.22 \\
-0.71\end{array}$ & $\begin{array}{l}<\overline{0.05} \\
<0.01\end{array}$ \\
\hline
\end{tabular}

Only parameters giving significant changes following injections of the hormones have been included (see text).

$\Delta R_{a}=\Delta R$ of the amplitude; $\Delta R_{f}=\Delta R$ of the frequency; $\Delta R_{d}=\Delta R$ of the duration.

correlation between $\Delta \mathrm{R}$ and the frequency of contractions. However, $\Delta \mathrm{R}$ for the amounts of vasopressin studied was correlated negatively with the duration of contractions $(P<0 \cdot 01)$. The effect of vasopressin upon duration seemed to be more pronounced when the contractions lasted for a long period of time.

In the proximal part of the vas deferens, there was a significant negative correlation $(P<0.05)$ between $\Delta \mathrm{R}$ and the amplitude only after injections of $100 \mathrm{~m}$-i.u. of vasopressin. In addition, $\Delta \mathrm{R}$ for this dose of vasopressin was correlated negatively with the frequency $(P<0.001)$. Apparently, the higher dose of vasopressin has an increased capacity to stimulate the amplitude as well as the frequency of the contractions in those preparations which have poorly developed muscular activity.

This analysis shows that the effects of the neurohypophysial hormones are not dependent on the amplitude and the frequency of the contractions, except in the proximal part of the vas deferens after infusion of the high dose of vasopressin (Table 3). With this exception, the facts eliminate the possibility that the observed differences in these parameters between the response to the hor- 
mones of the various parts of the genital tract investigated could have been conditioned by the experimental situation. The present observations thus indicate a heterogeneous distribution of the receptors sensitive to neurohypophysial hormones in the different parts of the male genital tract. The effects of oxytocin on the analogous organs in the female-the oviduct-uterus complex, may also be considered. These organs have been found to have a polarity in their muscular response to the hormone (Sandberg, Ingelman-Sundberg, Lindgren \& Rydén, 1961, and others).

In agreement with the present data, Gross \& Glover (1958) were unable to find any effect of oxytocin and vasopressin on the contractions of the vesicula seminalis in vivo. Earlier investigations of the effects of oxytocin on the motility of the vas deferens and the epididymis are somewhat contradictory but the majority of these observations disagree with the present findings (Waddell, 1916, 1917; Perutz \& Merdler, 1924; Martins \& Valle, 1939; Martins, Valle \& Porto, 1940; Wojcik, 1966). All these studies, however, were performed in vitro and were based on the muscle-lever and kymographic technique, which seems too insensitive for the recording of small manifestations of contractile activity, in that the longitudinal contractions of the organ will mainly be recorded. Cross (1959) reports no effect of oxytocin on the contractility of the epididymis of anaesthetized rabbits. However, as no data were presented, it seems difficult to draw any definite conclusions from these observations. It must be kept in mind that the present effects of oxytocin on the contractility of the genital organs, though significant, are moderate.

The observed effects of oxytocin and vasopressin on male genital tract motility must by mediated by a direct mechanism. The latency (10 to 15 sec) seems too short for vascular changes, for example, to produce any alteration of muscular activity. On the other hand, such a mechanism may operate to give the biphasic response observed in the present investigation after injections of oxytocin and particularly of vasopressin (Plate 1). A similar response was also apparent after injections of adrenalin (Plate 1), the later part of which was characterized by a lowering of the muscular tone and sometimes followed by a temporary inhibition of the muscular contractions. The inhibitory effect of adrenalin on the contractility of the male genital organs has also been noted by Cross (1959).

It is well known that a varying response of the uterus to oxytocin occurs during the sexual cycle, as well as during pregnancy. Even in males, the importance of sex hormones for the effect of oxytocin has been considered (Honoré \& Lloyd, 1961; Kihlström \& Melin, 1963; Niemi \& Kormano, 1965). Accordingly, the possible existence of a sexual cycle in males (Kihlström, 1966) may explain the great individual variations observed, not only of the motility of the genital organs in untreated animals (Melin, 1970) but also of their responses to the neurohypophysial hormones found in the present investigation. There may well be an underlying hormonal factor to account for the fact that an injection of $100 \mathrm{~m}$-i.u. of oxytocin increases the amplitude in the ductus epididymidis in one animal but decreases the same parameter in another individual.

The failure of the higher dose of oxytocin to influence the amplitude of the contractions in the ductus epididymidis and the proximal part of the vas 
deferens is partly caused by the increased number of preparations showing a reduction in amplitude of contraction as a result of hormone injection. These findings, as well as the significant lessening in the muscular tone of the distal part of the vas deferens caused by oxytocin, may be related to the observations of Wojcik (1966), who found a reduction in longitudinal muscle activity and in the tone of the male genital organs in response to high doses of oxytocin. The hormone may have qualitatively different effects on the longitudinal and circular muscle elements of the male genital tract.

The lower dose of oxytocin $(20 \mathrm{~m}-\mathrm{i} . \mathrm{u} . / \mathrm{kg})$ used in the present experiments, corresponds to, or is less than, the amounts of the hormone endogenously released by faradic or physiological stimuli (Harris, 1948; Cross, 1955; Hawker, 1961; Fuchs \& Wagner, 1963; Fuchs, 1964). These facts suggest that at least the effects produced by $20 \mathrm{~m}$-i.u. of oxytocin may be of physiologicalsignificance. Moreover, the inhibitory effect of anaesthesia on the action of oxytocin (which may be valid for vasopressin as well) must be considered (Fuchs \& Wagner, 1963). Consequently, in order to reproduce the effects of the hormones in anaesthetized animals, it is probably necessary to use amounts of the substances that appear unphysiological. The present highly significant effects of $20 \mathrm{~m}$-i.u. of oxytocin and vasopressin (as well as the tetanic effect of this dose of vasopressin) in the ductus epididymidis indicate a supra-threshold dose.

The present observations support the theory that the effects of oxytocin on the male sexual function, referred to earlier, are partly caused by the action of this hormone on the contractile elements of the genital organs. This investigation indicates that vasopressin may also be important in this respect. It appears that there is a gradual increase of the effects of the neurohypophysial hormones towards the testis. The findings agree with observations in rats by Niemi \& Kormano (1965) on the influence of oxytocin on the contractility of the seminiferous tubules. Of course, the more testicular parts of the male genital ducts are the most logical target organs for the hormones studied. It is noticeable that oxytocin and vasopressin in the lowest doses used, exclusively affect the amplitude and frequency respectively. In view of the simultaneous release of the hormones from the neurohypophysis (Heller, 1961), these observations indicate complementary effects of the hormones on the male genital tract.

\section{ACKNOWLEDGMENTS}

This investigation was supported by grants from the Magnus Bergwall and Hierta-Retzius Foundations and from the Faculty of Mathematics and Science of the University of Uppsala. For helpful criticism, I am much indebted to Dr J. E. Kihlström and Professor P. E. Lindahl. Oxytocin (Partocon) and lysine-vasopressin (Postacton) were generously supplied by Ferring AB, Malmö, Sweden.

\section{REFERENCES}

Bereznev, A. P. (1963) Oxytocin a stimulator of semen emission in bulls. (In Russian). Seljskochozjaistvennoi Nauki. 8, 91.

CRoss, B. A. (1955) Neurohormonal mechanisms in emotional inhibition of milk ejection. F. Endocr. $12,29$. 
Gross, B. A. (1959) Hypothalamic influences on sperm transport in the male and female genital tract. In: Endocrinology of Reproduction, p. 167. Ed. C. W. Lloyd. Academic Press, New York.

Cross, B. A. \& Glover, T. D. (1958) The hypothalamus and seminal emission. 7. Endocr. 16, 385.

Csapo, A. (1961) The effects of oxytocic substances on the excitability of the uterus. In: Oxytocin, p. 100. Eds. R. Caldeyro-Barcia and H. Heller. Pergamon Press, London.

Ewy, Z. \& Bielansky, W. (1962) Influence of oxytocin on spermatozoa transport in the ductus deferens in the ram. Proc. int. Union. Physiol. Sci. 11, No. 545.

Fjellström, D., Kinlström, J. E. \& Melin, P. (1968) The effect of synthetic oxytocin upon seminal characteristics and sexual behaviour in male rabbits. 7. Reprod. Fert. 17, 207.

Fuchs, A. R. (1964) Oxytocin and the onset of labour in rabbits. 7. Endocr. 30, 217.

Fughs, A. R. \& WAGNeR, G. (1963) Quantitative aspects of release of oxytocin by suckling in unanaesthetized rabbits. Acta endocr., Copenh. 44, 581.

Harris, G. W. (1948) Further evidence regarding the endocrine status of the neurohypophysis. 7 . Physiol., Lond. 107, 436.

HAWkeR, R. (1961) Oxytocin and an unidentified oxytocic substance in extracts of blood. In: Oxytocin, p. 425. Eds. R. Caldeyro-Barcia and H. Heller. Pergamon Press, London.

Heller, H. (1961) Occurrence, storage and metabolism of oxytocin. In: Oxytocin, p. 3. Eds. R. CaldeyroBarcia and H. Heller. Pergamon Press, London.

HoNORE, L. H. \& LLOYD, S. (1961) The effects of castration on the vascular responses of male rats to posterior pituitary hormones. 7. Physiol., Lond. 159, 183.

Kinlström, J. E. (1966) A sex cycle in the male. Experientia, 22, 630.

Kinlström, J. E. \& Melin, P. (1963) The influence of oxytocin upon some seminal characteristics in the rabbit. Acta physiol. scand. 59, 363 .

Levin, K. L. (1966) The effect of oxytocin and proserine on increased sperm production in hogs. (In Russian). Veterinariyja, 43, 96.

Martins, T. \& VAlLE, J. R. (1939) Endocrine control of the motility of the male accessory genital organs. Endocrinology, 25, 80.

Martins, T., Valle, J. R. \& Porto, A. (1940) Pharmacology in vitro of the human vasa deferentia and epididymis: the question of the endocrine control of the motility of the male accessory genitals. 7. Urol. 44, 682 .

Melin, P. (1970) In vivo recording of contractile activity of male accessory genital organs in rabbits. Acta physiol. scand. 79, (in press).

Melin, P. \& Kinlström, J. E. (1963) Influence of oxytocin on sexual behavior in male rabbits. Endocrinology, 73, 433.

Niemi, M. \& Kormano, M. (1965) Contractility of the seminiferous tubule of the postnatal rat testis and its response to oxytocin. Annls Med. exp. Biol. Fenn. 43, 40.

Perutz, A. \& Merdler, M. (1924) Beiträge zur experimentellen Pharmacologie des männlichen Genitales. Arch. Derm. Syph. 148, 104.

Sandberg, F., Ingelman-Sundberg, A., Lindgren, L. \& Rydén, G. (1961) The effect of oxytocin on the motility of the different parts of the pregnant and nonpregnant human uterus in vitro as compared with other oxytocic drugs. In: Oxytocin, p. 295. Eds. R. Caldeyro-Barcia and H. Heller. Pergamon Press, London.

Sjöstrand, N. O. \& Swedin, G. (1968) Potentiation by smooth muscle stimulants of the hypogastric nerve-vas deferens preparation from normal and castrated guinea-pigs. Acta physiol. scand. 74, 472 .

Waddell, J. A. (1916) The pharmacology of the vas deferens. 7. Pharmac. exp. Ther. 8, 551.

Waddell, J. A. (1917) The pharmacology of the uterus masculinus. 7. Pharmac. exp. Ther. 9, 171.

Wojcik, K. (1966) Mechanisms of transport in the male genital organs. 1. Action of cholinergic and adrenergic mediators and hypothalamic hormones on contractions of isolated preparations of rabbits' genital organs. Acta physiol. pol. 17, 78. 